EGU2020-22579

https://doi.org/10.5194/egusphere-egu2020-22579

EGU General Assembly 2020

(c) Author(s) 2021. This work is distributed under

the Creative Commons Attribution 4.0 License.

\title{
Monitoring the last Apennine glacier: recent in situ campaigns and modelling of Calderone glacial apparatus
}

\author{
Elena Pettinelli ${ }^{1}$, Massimo Pecci ${ }^{2}$, Frank S. Marzano 3,4, Marianna Biscarini ${ }^{3}$, Paolo Boccabella ${ }^{4}$, \\ Federica Bruschi ${ }^{5}$, Tiziano Caira ${ }^{2}$, David Cappelletti ${ }^{2,5}$, Domenico Cimini ${ }^{4}$, Pinuccio D'Aquila ${ }^{2}$, \\ Thomas Di Fiore ${ }^{4}$, Giulio Esposito ${ }^{6}$, Sebastian E. Lauro ${ }^{1}$, Elisabetta Mattei ${ }^{1}$, Angelo Monaco ${ }^{4}$, \\ Gianluca Palermo ${ }^{3}$, Mattia Pecci ${ }^{4}$, Edoardo Raparelli ${ }^{3,4}$, Marco Scozzafava ${ }^{4}$, and Paolo Tuccella ${ }^{4}$ \\ ${ }^{1}$ Roma Tre University - DMF \\ ${ }^{2}$ Italian Glaciological Committee (CGI) \\ ${ }^{3}$ Sapienza University of Rome -DIET \\ ${ }^{4}$ CETEMPS - University of L'Aquila \\ ${ }^{5}$ University of Perugia, DBCC \\ ${ }^{6}$ National Research Council (CNR) - IIA
}

The Calderone glacier is at present the most southern glacier in Europe $\left(42^{\circ} 28^{\prime} 15^{\prime \prime} \mathrm{N}\right)$. The little apparatus (about $20.000 \mathrm{~m}^{2}$ in surface area) has been giving an interesting response both to shortand long-term climatic variations which resulted in a considerable reduction in surface area and volume. The glacial apparatus is split into two ice bodies (glacierets) since 2000. The two glacierets are located in a deep northward valley below the top of the Corno Grande (2912 m asl) in the centre of the Gran Sasso d'Italia mountain range (Central Italy). Such glacial apparatus has been subjected to a strong reduction, with a loss of total surface area of about $50 \%$ and thickness of about $65 \%$ with respect to the hypothetical size (about $105.00 \mathrm{~m}^{2}$ and $55 \mathrm{~m}$ at the Little Ice Age).

Since early 90s the Calderone glacier has been subjected to several multidisciplinary field campaigns to monitor and evaluate its role as an environmental indicator in the framework of global warming. Starting from historical series related to more than a century of records, the variability of the different glacier properties has been estimated by using classical geomorphologic methods as well as in situ and remote sensing techniques. In particular, the last field campaigns, in 2015, 2016 and 2019, have been carried out using Ground Penetrating Radar equipped with different antenna frequencies, drone-based survey, snow pit measurements and chemicalphysical sampling. The measurement campaigns have been complemented by a regional climate analysis, spanning the last fifty years, and snowpack modelling initialized with microphysical snow data (e.g., snow density, crystal shape and size, hardness). The snowpack chemical analyses include the main and trace elements, soluble inorganic and organic ions, EC/OC and PAH, with different spatial resolution depending on the analytes. We present here the methodological approach used and some preliminary results. 